\title{
Differential infection properties of three inducible prophages from an epidemic strain of Pseudomonas aeruginosa
}

Chloe E James ${ }^{1 *}$, Joanne L Fothergill', Hannes Kade, Amanda J Hall ,'Jennifer Cottell ,' Michael A Brockhurst ${ }^{2+}$ and Craig Winstanley ${ }^{1+}$

\begin{abstract}
Background: Pseudomonas aeruginosa is the most common bacterial pathogen infecting the lungs of patients with cystic fibrosis (CF). The Liverpool Epidemic Strain (LES) is transmissible, capable of superseding other $P$. aeruginosa populations and is associated with increased morbidity. Previously, multiple inducible prophages have been found to coexist in the LES chromosome and to constitute a major component of the accessory genome not found in other sequenced $P$. aerugionosa strains. LES phages confer a competitive advantage in a rat model of chronic lung infection and may, therefore underpin LES prevalence. Here the infective properties of three LES phages were characterised.

Results: This study focuses on three of the five active prophages (LES $\varphi 2$, LES $\varphi 3$ and LES $\varphi 4$ ) that are members of the Siphoviridae. All were induced from LESB58 by norfloxacin. Lytic production of LES $\varphi 2$ was considerably higher than that of LES $\varphi 3$ and LES $\varphi 4$. Each phage was capable of both lytic and lysogenic infection of the susceptible P. aeruginosa host, PAO1, producing phage-specific plaque morphologies. In the PAO1 host background, the LES $\varphi 2$ prophage conferred immunity against LES $\varphi 3$ infection and reduced susceptibility to LES $\varphi 4$ infection. Each prophage was less stable in the PAO1 chromosome with substantially higher rates of spontaneous phage production than when residing in the native LESB58 host. We show that LES phages are capable of horizontal gene transfer by infecting $P$. aeruginosa strains from different sources and that type IV pili are required for infection by all three phages.
\end{abstract}

Conclusions: Multiple inducible prophages with diverse infection properties have been maintained in the LES genome. Our data suggest that $\operatorname{LES} \varphi 2$ is more sensitive to induction into the lytic cycle or has a more efficient replicative cycle than the other LES phages.

Keywords: Pseudomonas aeruginosa, Prophage induction, Bacteriophage infection, Cystic fibrosis, Host range, Type IV pili

\section{Background}

Pseudomonas aeruginosa is a versatile Gram-negative bacterium, able to metabolise multiple carbon sources and exploit diverse ecological niches, e.g. soil, water, plants and animal hosts [1,2]. This opportunistic pathogen causes a range of human infections, including acute infections of severe wounds [3] and burns [4,5] and

\footnotetext{
* Correspondence: cejames@liv.ac.uk

'Equal contributors

'Institute of Infection and Global Health, University of Liverpool, 8 West Derby Street, Liverpool L69 7BE, UK

Full list of author information is available at the end of the article
}

chronic lung infections in cystic fibrosis (CF) patients [6]. P. aeruginosa forms biofilms in the CF lung that are highly resistant to antibiotics and clearance by the immune system [7]. Once established, such biofilms cannot be eradicated and are associated with greatly increased morbidity and mortality [8].

Several CF-associated transmissible strains of $P$. aeruginosa, capable of between patient transmission, have been identified in the UK, Europe, Australia and North America [9]. The Liverpool Epidemic Strain (LES), a UK transmissible strain, was first isolated in

\section{Biomed Central}


1996 at Alder Hey Children's Hospital (AHCH), Liverpool [10]. This strain is capable of super-infection, supplanting pre-existing $P$. aeruginosa populations in the CF lung [11]. Chronic infection with LES is associated with increased morbidity and mortality compared to other $P$. aeruginosa strains [12]. The LES is highly prevalent within individual hospital CF units [13] and is the most abundant $P$. aeruginosa strain amongst CF patients in the UK [14]. It was also recently isolated from the sputa of CF patients in North America [15].

Sequencing of the earliest LES isolate, LESB58, demonstrated that the genome shares 95\% similarity with the lab strain PAO1. However, its core genome is punctuated by multiple norfloxacin-inducible prophages [16]. Specifically, there are five inducible prophage genomes (LES $\phi 2$; LES $\phi 3 \operatorname{LES} \phi 4 \operatorname{LES} \phi 5$ and LES $\phi 6)$ that are mosaic in nature. The gene organisation of LES $\phi 2$ and LES $\phi 3$ resembles that of lambdoid phages. These two phage genomes share $82.2 \%$ identity across a $13.6-\mathrm{kb}$ region at their 3' ends that makes up $32 \%$ of the phage genomes. The closest known relative to both these phages is the Pseudomonas phage F10 [17]. LES $\phi 3$ also contains a $7.5 \mathrm{~kb}$ region that shares $99.8 \%$ homology with LES $\phi 5$, which exhibits a considerable sequence similarity to the O-antigen converting phage D3 [18]. $\mathrm{LES} \phi 4$ is a transposable Mu-like phage that closely resembles phage D3112 [19]. The LES 66 sequence resembles a pf1-like filamentous phage [16].

Temperate phages have been shown to confer selective, beneficial traits to a range of $P$. aeruginosa hosts [20]. For example, phage D3 orchestrates O antigen conversion from $\mathrm{O} 5$ to $\mathrm{O} 16$ in PAO1, which may aid evasion of the immune system and resistance to phage superinfection $[18,21]$. Phage $\phi C T X$ infection of PAS10 results in conversion to a toxigenic strain [22] and the filamentous phage, Pf1, has been associated with biofilm disruption and dispersal [23]. LES prophages have been suggested to contribute to the competitiveness of their bacterial host in vivo. LESB58 mutants, with disrupted prophage genes, exhibited 10 to 1000-fold decreased competitiveness in a rat model of chronic lung infection compared to wild type LESB58 [16]. The LES phages are induced by exposure to clinically relevant antibiotics, e.g. ciprofloxacin [24], and free LES phages and other tailedphage virions have been detected in CF patient sputa $[25,26]$.

Temperate phages are key vectors of horizontal gene transfer (HGT) [27]. Therefore, it is important to assess the ability of the LES phages to infect other bacterial hosts to which they may confer traits beneficial to life in the CF lung environment. Here we describe the infection characteristics of three of the five LES prophages $\operatorname{LES} \phi 2$,
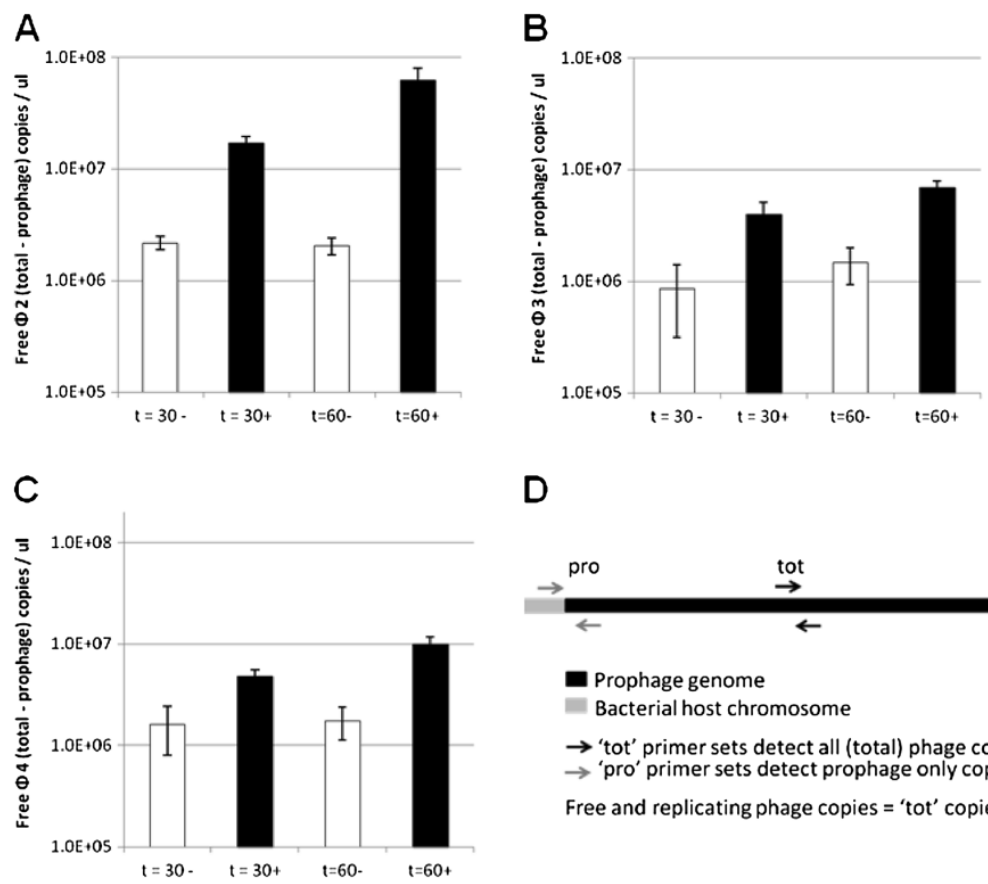

D

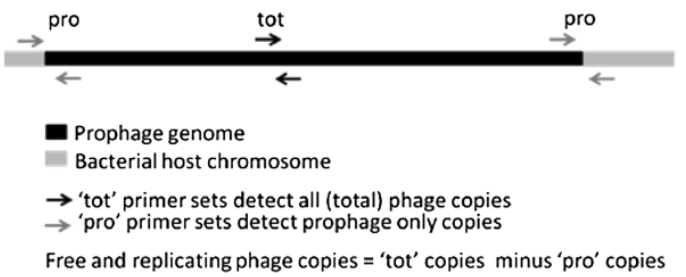

Figure 1 Exposure to sub-inhibitory concentrations of norfloxacin induces the lytic cycle of three LES phages. Mid-exponential phase LESB58 cultures $\left(\mathrm{OD}_{600}\right.$ 0.5) were exposed to sub-inhibitory norfloxacin $\left(50 \mathrm{ug} \mathrm{ml}^{-1}\right)$ for 30 and $60 \mathrm{~min}$ before recovery for $2 \mathrm{~h}$ and total DNA extraction. Total phage vs prophage numbers were quantified by Q-PCR with SYBR green and specific primers. Graphs show the production levels of each phage over time; A: $\operatorname{LES} \varphi 2 ; \mathbf{B}$ : $\operatorname{LES} \varphi 3 ; \mathbf{C}: \operatorname{LES} \varphi 4$. + norfloxacin; $\square$ - norfloxacin. D: Quantities of free phage were calculated by deducting prophage numbers from total phage numbers. The average free phage numbers at each time interval were plotted and Standard error is shown. Three independent experimental repeats were performed, each with 3 technical repeats. 
LES $\phi 3$ and LES $\phi 4$, induced from the sequenced CF lung isolate LESB58.

\section{Results}

\section{LES phage morphology}

Three different Siphoviridae phages were induced from LESB58 cultures and visualised using electron microscopy. The phages possessed icosahedral heads (50-60 nm diameter) and long flexible tails (approximately $200 \mathrm{~nm}$ ). Plaque assay of each phage on PAO1 resulted in the formation of small turbid plaques with different phage-specific morphologies. LES $\phi 3$ plaques were the largest $(2-3 \mathrm{~mm})$, with well-defined lysogen islands, whereas LES $\phi 2$ plaques were considerably smaller $(0.5-1.5 \mathrm{~mm})$. LES $\phi 4$ produced plaques with small, clear centres surrounded by a turbid halo. The identity of each LES phage responsible for the different plaque morphologies was confirmed using a multiplex PCR assay.

\section{Differential induction of LES phages from LESB58}

The sensitivity of the LES phages to induction into the lytic cycle was determined and compared. Real-time quantitative (Q)-PCR was used to measure relative increases in phage DNA copy number following induction by exposure of LESB58 to norfloxacin. After exposure to norfloxacin for $60 \mathrm{~min}$ and recovery for $2 \mathrm{~h}$, LES $\phi 2$ was the most abundant free phage detected $\left(6.2 \times 10^{7}\right.$ copies $\left.\mu \mathrm{l}^{-1}\right)$, compared to $\operatorname{LES} \phi 3\left(6.9 \times 10^{6}\right.$ copies $\left.\mu l^{-1}\right)$ and LES $\phi 4\left(1 \times 10^{7}\right.$ copies $\left.\mu l^{-1}\right)$ (Figure 1). Furthermore, the increase in LES $\phi 2$ production between 30 and $60 \mathrm{~min}$ exposure times was higher (3.67 fold increase) than that for LES $\phi 3$ (1.74 fold increase) and LES $\phi 4$ (2.06 fold increase). Thus while norfloxacin induction caused a significant increase in the replication of all three phages (LES $\phi 2-\mathrm{F}_{1,8}$ 56.97, P 0.001; LES $\phi 3-\mathrm{F}_{1}$, 8 14.02, P 0.006; LES $\phi 4-F_{1,8} 16.88$, P 0.003), only LES $\phi 2$ showed significantly greater phage production after $60 \mathrm{~min}$ compared to $30 \mathrm{~min}$ norfloxacin exposure (induction"time interaction, $\left.F_{1,8} 20.90, \mathrm{P} 0.002\right)$; by contrast, the duration of exposure had no effect on phage production in LES $\phi 3$ and LES $\phi 4$ (induction"time interaction, LES $\phi 3-F_{1,8}$ 1.05, P 0.336; LES $\phi 4-F_{1,8} 3.19$, P 0.112). We suggest therefore that LES $\phi 2$ is either more sensitive to induction by norfloxacin or that it replicates more rapidly once induced.

\section{Lysogenic infection of a model PAO1 host}

PAO1 LES phage lysogens (PLPLs) were created by infection of strain PAO1 with each LES phage and isolation of single colonies from turbid areas within plaques (Figure 2). Challenge of PLPLs with different LES phages, using plaque assays, revealed varying immunity profiles. Table 1 lists the efficiency of plating (eop)

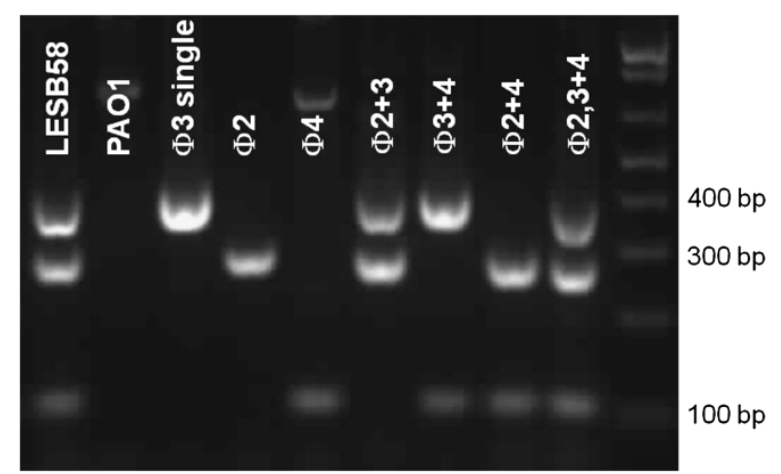

Figure 2 PCR confirmation of all PAO1 LES phage lysogens. Lysogens were isolated from turbid plaques following sequential infection of PAO1 with pure stocks of each LES phage. Lysogens were considered resistant if no plaques were observed following exposure to increasingly high titre phage suspensions (up to $\mathrm{MOI}$ 100). The presence of each prophage was confirmed using multiplex PCR with specific primer sets for each LES phage yielding differentially sized products: 325 bp (LES 43$) ; 250$ bp (LES 42$) ; 100$ bp (LES $\varphi$ 4).

values of each LES phage on each PLPL lawn. Prophages 2 and 3 conferred immunity to super-infection by LES $\phi 2$ and LES $\phi 3$ respectively (eop $\left.<1 \times 10^{-9}\right)$. However, a few LES $\phi 4$ super-infection events were observed by detection of plaques following exposure of lysogens to $1 \mathrm{x}$ $10^{10}$ p.f.u ml ${ }^{-1}$ of LES $\phi 4$ (eop $\left.=3.33 \times 10^{-9}\right)$. LES $\phi 2$ was able to infect PLPLs harbouring prophages LES $\phi 3$ (eop 0.91) and LES $\phi 4$ (eop 1.09) at the same efficiency as non-lysogenic PAO1. However, lysogens harbouring the LES $\phi 2$ prophage were resistant to infection by $\operatorname{LES} \phi 3$ $\left(\right.$ eop $\left.<1 \times 10^{-9}\right)$ and showed considerably reduced susceptibility to LES $\phi 4$ (eop 0.017).

Spontaneous phage production by all seven PLPLs was higher than that associated with LESB58, by $5-6$ orders of magnitude $(\mathrm{P}<0.05)$ (Figure 3$)$. These data suggest that LES prophages are less stable in PAO1, with significantly higher rates of spontaneous lytic phage production than in LESB58. Little difference was observed in

\section{Table 1 Differential Immunity profiles of each LES phage} in PAO1

\begin{tabular}{lccc}
\hline Efficiency of plating values & $\boldsymbol{\varphi 2}$ & $\boldsymbol{\varphi 3}$ & $\boldsymbol{\varphi} \mathbf{4}$ \\
\hline PAO1 naive host & 1.0 & 1.0 & 1.0 \\
Single $\varphi 2$ lysogen & $<1 \times 10^{-9}$ & $<1 \times 10^{-9}$ & 0.017 \\
Single $\varphi$ 3 lysogen & 0.91 & $<1 \times 10^{-9}$ & 0.37 \\
Single $\varphi 4$ lysogen & 1.09 & 0.94 & $3.3 \times 10^{-9}$ \\
\hline
\end{tabular}

Immunity profiles of each LES phage were determined by plaque assay. Phage dilution series were spotted onto non-Lysogenic PAO1 and PLPL lawns. Efficiency of plating = the ratio of plaques observed (at the appropriate phage dilution) on the most permissive host (non-lysogenic PAO1)/plaques observed on assay host (PLPL harbouring $\operatorname{LES} \varphi 2, \operatorname{LES} \varphi 3$ or $\operatorname{LES} \varphi 4$ prophages). If no plaques were observed when neat phage suspensions of $10^{10}$ p.f.u ml $l^{-1}$ were used, an eop value $<1 \times 10^{-9}$ was recorded. 


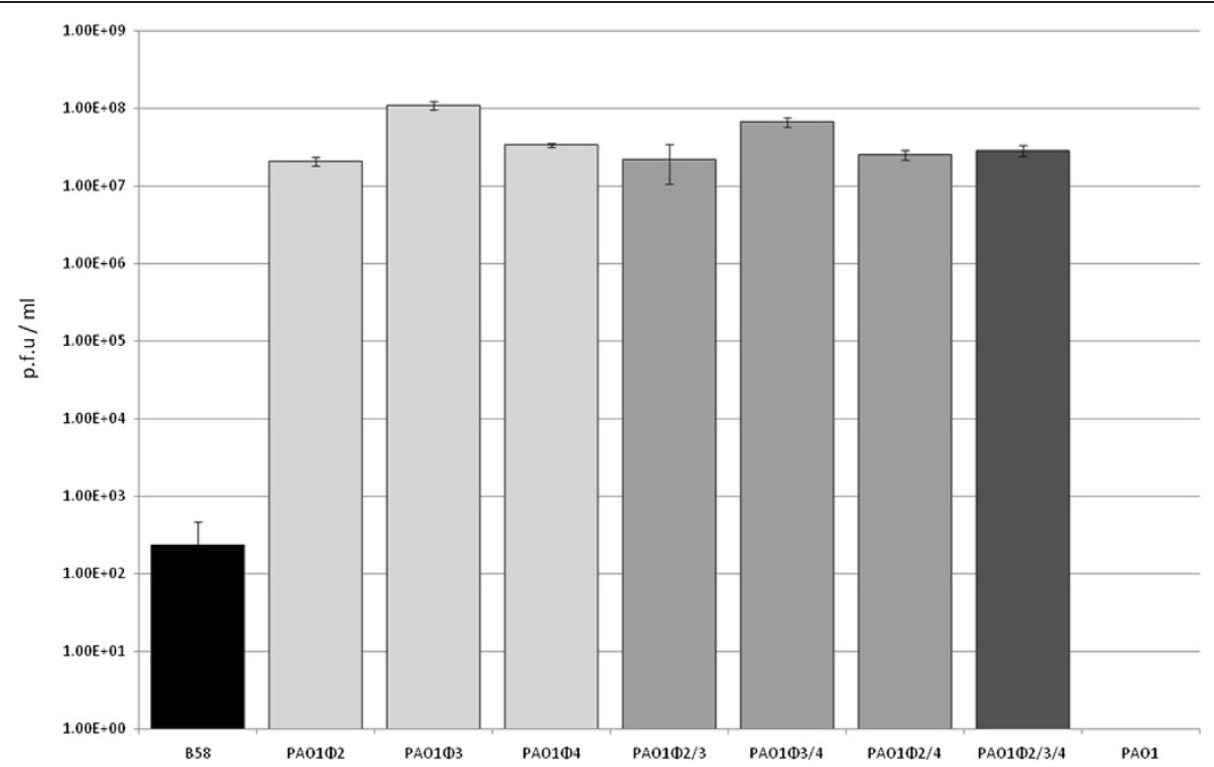

Figure 3 Spontaneous lysis exhibited by LES phages in PAO1 vs LESB58. Phage production was quantified from filtered culture supernatants of un-induced mid-exponential phase cultures using standard plaque assay. Standard deviation is shown $(n=3)$.

the levels of spontaneous phage production between single, double and triple PAO1 lysogens.

\section{LES phages integrate at the same sites in different bacterial host strains}

Southern blot analysis was used to demonstrate that lysogenic instability was not due to integration of the LES phages into unstable sites of the naive PAO1 chromosome, or from multiple integration events of the same phage (Figure 4). LES $\phi 2$ and LES $\phi 3$ integrated as single copies at identical locations in LESB58 and PAO1 chromosomes.

The LES $\phi 2$ int probe hybridised to an additional DNA fragment in all lysogens containing LES $\phi 2$, including LESB58. The size of the additional hybridised fragment corresponds to one of two possibilities: 1) the integration of a second LES $\$ 2$ copy in to the chromosome directly downstream of the first; 2) an extra copy of LES $\phi 2$ in circular form (Figure 4). The published LESB58 genome sequence clearly shows a single LES $\phi 2$ copy in the chromosome. Since the hybridisation pattern of the PAO1 LES $\$ 2$ lysogen matches that of LESB58, a second chromosomal copy can be ruled out. This suggests that the extra copy is circular, which may represent phage replication resulting from spontaneous activation of the lytic life cycle. Alternatively, the extra copy may indicate pseudolysogeny, in which stable circular copies are maintained.

The LES $\phi 4$ cI probe indicated that LES $\phi 4$ is able to integrate in several chromosomal locations in PAO1.
LES phages infect a narrow host range in a type IV pilus-dependant manner

From a well-characterised panel of 32 clinical $P$. aeruginosa isolates, 6 were susceptible to LES phage infection. Of 25 environmental isolates, representing 17 different Pseudomonas species, only the $P$. aeruginosa strain was susceptible. In addition, PA14 was resistant to infection by $\operatorname{LES} \phi 2$ and $\operatorname{LES} \phi 3$, but susceptible to LES $\$ 4$. Plaques on PA14 appeared less turbid than those on PAO1 lawns. The host ranges of each LES phage were not identical and no correlation was found between bacterial clone-type [28] and susceptibility (data not shown). In addition, other common Gram-negative CF pathogens Burkholderia cenocepacia and B. multivorans strains were resistant to infection by all three LES phages (Table 2).

A non-piliated PAO1 mutant (pilA-) was resistant to infection by all 3 phages, suggesting that LES $\phi 2,3$ and 4 all require type IV pili for infection. The hyper-piliated mutant (pilT) was also resistant to the LES phages, whilst an alternative hyper-piliated mutant (pil $U^{-}$) remained fully susceptible.

\section{Discussion}

Differential induction among co-infecting prophages

Induction experiments demonstrated that LES $\phi 2$ virions were produced from LESB58 in greater numbers than the other phages. These data suggest that LES $\phi 2$ replication is more efficient than the other phages and could out number and therefore out compete the other, coinfecting LES phages during the lytic cycle. Potentially 


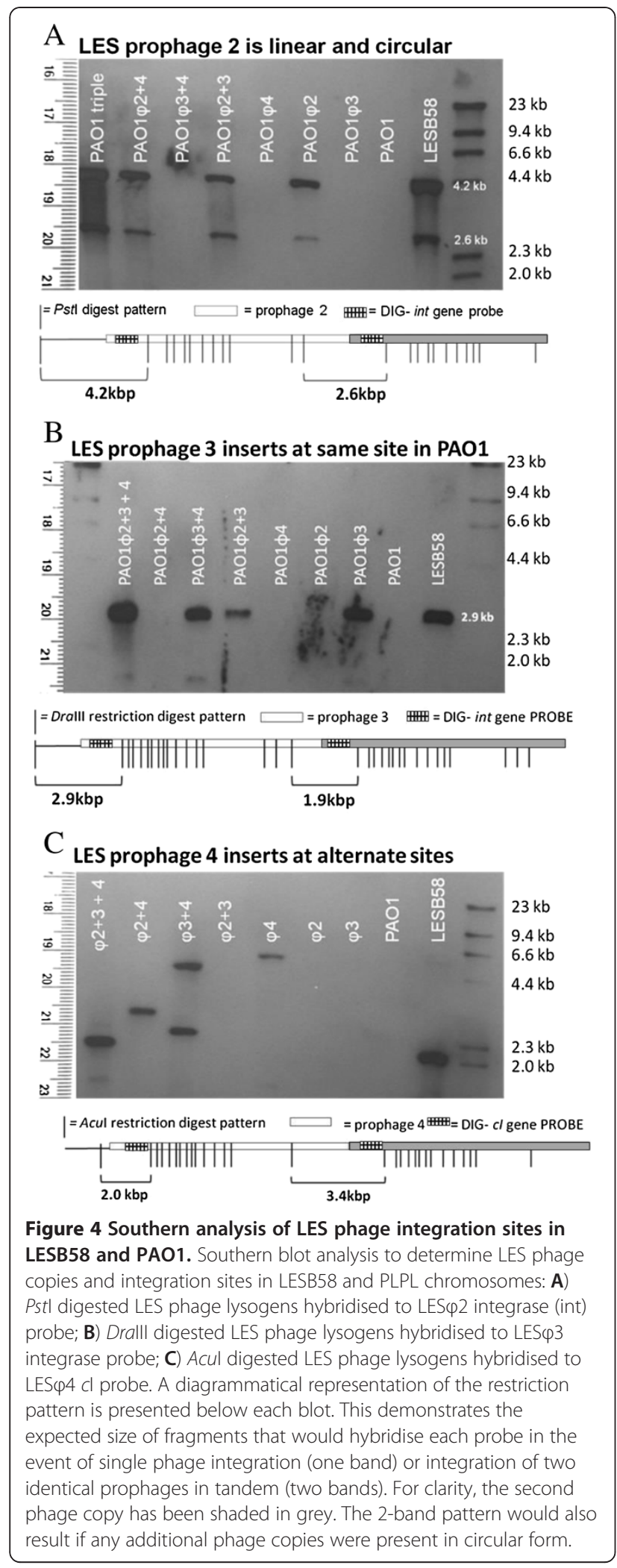

supporting this hypothesis, we detected an extra copy of this phage in the LES $\phi 2$ lysogen genome. Southern analysis suggests the presence of either a pseudo-lysogenic
Table 2 Susceptibility of a panel of Pseudomonas isolates to LES phages 2, 3 and 4

\begin{tabular}{lccc}
\hline Isolate source (\#) & $\boldsymbol{\varphi} \mathbf{2}$ & $\boldsymbol{\varphi 3}$ & $\boldsymbol{\varphi 4}$ \\
\hline Reference strains (2) & $50 \%(1 / 2)$ & $50 \%(1 / 2)$ & $100 \%(2 / 2)$ \\
Keratitis patient (12) & $8.3 \%(1 / 12)$ & $0 \%(0 / 12)$ & $33.3 \%(4 / 12)$ \\
Non-LES child (8) & $12.5 \%(1 / 8)$ & $0 \%(0 / 8)$ & $12.5 \%(1 / 8)$ \\
Non-LES adult (6) & $16.7 \%(1 / 6)$ & $0 \%(0 / 6)$ & $0 \%(0 / 6)$ \\
Anomalous LES (6) & $0 \%(0 / 6)$ & $0 \%(0 / 6)$ & $0 \%(0 / 6)$ \\
Environmental (25) & $0 \%(0 / 25)$ & $4 \%(1 / 25)$ & $0 \%(0 / 25)$ \\
\hline
\end{tabular}

Percentage of LES phage-sensitive strains as determined by plaque assay. Actual numbers tested are shown in parentheses.

plasmid form [29], or a highly active replicative form of LES $\phi 2$ during spontaneous phage production.

The implications of within-host competition between co-infecting prophages has been little studied, however Refardt et al. [30] observed hierarchical competition between multiple prophages in $E$. coli, which suggested that the sensitivity of the lytic switch can determine dominance of one prophage over another in a polylysogen. Carriage of phages that are very prone to activation of the lytic lifecycle may represent a significant cost to their host cells, and thus could be selected against in natural populations. However, while natural isolates of LES sampled from CF patient sputa often lack one or more of the LES prophages [25], there is no evidence that LES $\phi 2$ is more or less stably maintained than $\operatorname{LES} \phi 3$ or LES $\phi 4$.

\section{LES phages exhibit different immunity profiles}

Each phage conferred inhibition of superinfection by the same phage, although the Mu-like phage, LES $\phi 4$ was observed to infect LES $\phi 4$ lysogens at a very low frequency. This may represent the development of rare mutations that affect immunity functions. There are several examples of such mutations in phage $\mathrm{Mu}$ [31]. Repressor/operator coevolution has been suggested to be the driving force for the evolution of superinfection immunity groups of lambdoid phages [32]. The same may hold true for $\mathrm{Mu}$-like phages. For example, mutation of the operator region has been shown to affect binding of the repressor in $\mathrm{Mu}$ vir mutants [33].

Sequential infection of PAO1 with different LES phages revealed an interesting superinfection hierarchy. LES $\phi 3$ lysogens remained susceptible to LES $\phi 2$ and LES $\phi 4$; and LES $\phi 4$ lysogens were susceptible to LES $\phi 2$ and LES $\phi 3$. However, LES $\phi 2$ prevented infection by LES $\phi 3$ and greatly reduced susceptibility to LES $\phi 4$. Such uni-directional infection exclusion has been reported between other phages, and is commonly associated with super-infection exclusion genes such as the lambda rex genes [34] and $\operatorname{sie} A, \operatorname{sie} B$ and $a 1$ in the Salmonella phage, P22 [35-38]. 
It is likely that $\operatorname{LES} \phi 3$ and $\operatorname{LES} \phi 4$ prophages would have been acquired before $\operatorname{LES} \phi 2$, because the infection hierarchy suggests that prior acquisition of LES $\phi 2$ would have prevented subsequent LES $\phi 3$ and LES $\phi 4$ infection.

\section{LES prophages in PAO1 undergo spontaneous activation} to the lytic cycle at a far higher rate than in LESB58

High levels of spontaneous induction were observed in PLPLs, suggesting that lysogeny is relatively unstable in the PAOl genetic background. We show that phage production remained high between PLPLs containing one, two or three LES prophages, suggesting that polylysogens were no more or less stable than any single lysogens. Southern analysis confirmed that LES $\phi 2$ and LES $\phi 3$ integrated into the same position in PLPLs as they did in LESB58. Therefore, the instability of PLPLs was not due to prophage integration into unstable sites. LES $\phi 4$ integrated in several alternative sites in PLPLs. The sequence of this phage shares a high level of genome synteny and homology with the transposable Mu-like phage D3112 [16], whose random integration has been demonstrated to create mutations within the host chromosome. LES $\phi 4$ may play a similar role in LES genome evolution.

\section{The LES phages exhibit a narrow host-range}

Our investigation of the LES phage host range revealed narrow, overlapping host specificity. No association between bacterial clone-type and phage susceptibility was observed, although testing more strains may have identified a pattern. Despite the high proportion of resistant clinical isolates, our data show that LES phages are capable of infecting some $P$. aeruginosa strains isolated from keratitis patients and non-LES infected CF patients. LES phages have been detected in CF patients' sputa, and may therefore allow mobilisation of genes between $P$. aeruginosa strains $[25,26]$. By contrast, LES phages may allow LES to displace other $P$. aeruginosa strains during superinfection in the CF lung [11] by lysing susceptible resident strains [39].

\section{LES phage infection is Type IV pilus-dependent}

We demonstrate that LES phage infection is dependent on the type IV pilus, which is required by $P$. aeruginosa for adhesion, biofilm formation and twitching motility [40-42]. This important surface structure is commonly used as a receptor by diverse Pseudomonas phages [43]. Both non-piliated (pilA $)$ and hyper-piliated (pilT) PAO1 mutants were resistant to infection by all three LES phages. However, a different hyper-piliated mutant (pilU) remained susceptible. These findings mirror other pilin-dependent $P$. aeruginosa phage studies [43-45]. Hyper-piliated mutants are incapable of twitching motility due to abrogated pili retraction. These data suggest that retraction is involved in the infection process by LES $\phi 2$ $\operatorname{LES} \phi 3$ and LES $\phi 4$.

Despite infecting via an important and common surface structure, all three LES phages exhibited narrow host ranges and each showed strain specificities. For example, LES $\phi 4$ was able to infect PA14 and several keratitis isolates that were resistant to infection by the other LES phages. It is likely that many clinical strains of $P$. aeruginosa harbour prophages that may belong to the same immunity group and therefore exclude superinfection by one or more of the LES phages [20]. Alternatively, resistance could be achieved by loss or modification of the type IV pili receptor $[44,45]$.

\section{Conclusion}

In summary, we demonstrate that the LES phages exhibit differential sensitivities to induction, narrow host ranges and divergent infection behaviour in the model host PAO1 compared with the native LESB58 host background. Extensive genotypic and phenotypic variation has been observed in clinical LES populations [46], including changes in the number of resident LES prophages [25]. These phages may, therefore, be important contributors to diversity of the LES populations.

\section{Methods}

\section{Bacterial strains and growth conditions}

All bacterial strains used in this study and their sources are listed in Table 3. LES phages were induced from the sequenced CF P. aeruginosa isolate, LESB58 [16]. Strain PAO1 was susceptible to infection by all three LES phages and was therefore used as a model host to purify and study the characteristics of each phage. Successive infection of PAO1 with purified LES phages yielded single, double and triple PAO1 LES Phage Lysogens (PLPLs) each harbouring single copies of one, two or three LES phages simultaneously. All lysogens were confirmed by PCR amplification of specific prophage sequences and Southern blot analysis. Non-piliated (pilA ${ }^{-}$) or hyperpiliated (pilT and pilU) PAO1 mutants [47] were used to determine whether LES phages infect via the type IV pili. All bacterial strains and phages were grown and propagated in standard lysogeny broth (LB) at $37^{\circ} \mathrm{C}$ (clinical isolates) or $23^{\circ} \mathrm{C}$ (environmental isolates). Phage suspensions were stored in $\mathrm{LB}$ at $4^{\circ} \mathrm{C}$.

\section{Bacteriophage induction}

$P$. aeruginosa LESB58 was grown to mid-exponential phase $\left(\mathrm{OD}_{600} 0.5\right)$ and LES phages were induced into the lytic cycle by exposure to the minimum inhibitory concentration of norfloxacin $\left(50 \mu \mathrm{g} \mathrm{ml}^{-1}\right)$ for $1 \mathrm{~h}$ [24]. Induced cultures were sub-cultured (1:10) into fresh LB to enable recovery for $2 \mathrm{~h}$ before filtration $(0.2 \mu \mathrm{m}$ Millipore). Active phage particles in the induced supernatants 
Table 3 Bacterial strains and sources

\begin{tabular}{ll}
\hline Strain ('Clone type) & $\begin{array}{l}\text { Reference/ } \\
\text { source }\end{array}$ \\
\hline
\end{tabular}

Laboratory P. aeruginosa strains:

PAO1(W)

PAO1 pilA-; PAO1 pilU-; PAO1 pilT- $^{2}$

PA14(A)

\section{Clinical LES isolates:}

LESB 58 (T) - Sequenced isolate

LES 431 (T) - Lacks LES prophage 2

Anomalous LES isolates ${ }^{3}$ :

O69574 (T); 0521 (T); 43513 (T); 079444 (T); 0342 (T).

P. aeruginosa isolates from keratitis patients ${ }^{4}$ :

39015 (B); 39115 (A); 39103 (A2);

39145 (A3); 39053 (A5); 39135 (C);

39016 (D); 39421 (F); 39061 (I);

39284 (L); $39376(\mathrm{U}) ; 39129$ (V).

\section{$P$. aeruginosa isolates from non-LES infected CF patients:}

CHILDREN: $\mathrm{AH} 23$ (B); $\mathrm{AH} 4(\mathrm{~A})$;

$\mathrm{AH} 19$ (A3); $\mathrm{AH} 14$ (C); $\mathrm{AH} 1$ (D);

AH6 (L); AH9 (U); AH7 (A4);

ADULTS: NL28 (A); NL20 (C);

NL25 (F); NL16 (U); NL21 (A4); NL14 (A7).

$\begin{array}{ll}\text { Environmental Pseudomonas spp: } & \text { Strain } \\ \text { P. aeruginosa } & 159 \\ \text { P. fluorescens } & \text { WC5365; F113; } \\ & \text { ATCC 17400; } \\ \text { pf5; pf01. } & \text { 'tomato' DC300; } \\ \text { P. syringae } & \text { B728a } \\ & \text { Ccola } \\ \text { P. syringae pv. Coriandricola } & \text { M4 } \\ \text { P. syringae pv. maculocola } & 152 \mathrm{E} \\ \text { P. syringae pv. antirrhini } & \mathrm{KT} 2440 ; \\ \text { P. putida } & \text { PaW340 } \\ \text { P. cichori } & 907 \\ \text { P. avellanae } & 48 \\ \text { P. phaseiolicola } & 1448 \mathrm{~A} \\ \text { P. entomophila } & \mathrm{L} 48 \\ \text { P. marginalis } & 247 \\ \text { P. corrugata } & 2445 \\ \text { P. tolaasii } & 2192 \mathrm{~T} \\ \text { P. glycinea } & 49 \mathrm{a} / 90 \\ \text { P. lachrymans } & 789 \\ \text { P. agarici } & 2472 \\ \text { P. viridiflava } & 2848\end{array}$

Table 3 Bacterial strains and sources (Continued)

\begin{tabular}{ll}
\hline B. cenocepacia & $\mathrm{K} 56-2 ; \mathrm{J} 2315$. \\
B. multivorans & $\mathrm{F}-\mathrm{A} 1-1 ;$ \\
& $\mathrm{LMG} 13010$. \\
\hline
\end{tabular}

${ }^{1}$ Clones typed using the Clondiag tube array system [51]; ${ }^{2}$ PAO1 pil mutants acquired from Angus Buckling, University of Exeter. ${ }^{3}$ Isolates classified as anomalous following negative diagnostic PCR result for one of two specific target sequences, but identified as LES using the tube array system. These isolates were also missing one or more LES prophage. ${ }^{4}$ Strains isolated from Keratitis patients from several hospitals across the UK. ${ }^{5} \mathrm{AHCH}$ : Isolates collected from child CF patients attending the Alder-Hey Children's Hospital, Liverpool. ${ }^{6}$ RLUH: Isolates collected from adult CF patients attending the Royal Liverpool University Hospital. ${ }^{7} \mathrm{RJ}$ Environmental isolates of several Pseudomonas species donated by R Jackson, University of Reading.

were enumerated by standard plaque assay using PAO1 host cells.

\section{Bacteriophage assays}

LES phages were isolated from induced LESB58 cultures using plaque assays with PAO1 host cultures as described previously [24]. Phages were purified by picking individual plaques that were suspended in LB $(1 \mathrm{ml})$, filter sterilized $(0.2 \mu \mathrm{m}$ Millipore $)$ and used in a second plaque assay with PAO1. This process was repeated twice to ensure purity. Phage purity was confirmed using PCR assays. Amplification of phage stocks was achieved by modifying previous methods [53]. Briefly, mid-exponential phase PAO1 cultures $(100 \mathrm{ml})$ were infected with purified LES phage $(\mathrm{MOI}=0.1)$, at $37^{\circ} \mathrm{C}$ for $2 \mathrm{~h}$. Lysed cultures were filter-sterilized.

\section{Electron microscopy}

Phage suspensions $\left(1 \times 10^{9}-1 \times 10^{10}\right.$ p.f.u. $\left.\mathrm{ml}^{-1}\right)$ were concentrated by centrifugation, negatively stained with $2 \%$ $(w / v)$ uranyl acetate [54], and examined by transmission electron microscopy (magnification x 200,000).

Multiplex PCR to confirm pure phage stocks and lysogens Three primer sets, LESnest1 F/R, Clust6nest F/R and 4tot1 F/R (Table 4), for the detection of LES phages 2, 3 and 4 respectively, were combined in a multiplex PCR assay for confirmation of each pure phage stock and each PLPL. Colony or filtered phage suspensions were used as templates in each reaction as described previously [25].

\section{Quantifying production of each LES phage from LESB58}

Replication of each LES phage in response to induction of the lytic cycle was compared using Q-PCR to distinguish and enumerate each specific phage type. LESB58 induction experiments were performed on three separate occasions in the presence and absence of norfloxacin for 30 and $60 \mathrm{~min}$ exposure times before the $2 \mathrm{~h}$ recovery step. DNA was prepared from each replicate using the Bacterial and Virus DNA extraction kit (QIAGEN) and the automated QIAsymphony machine (QIAGEN; 
Table 4 Primer sequences

\begin{tabular}{|c|c|c|c|c|}
\hline Primer & Sequence $(5 /-3 /)$ & Amplicon (bp) & Cycling conditions & Reference \\
\hline \multicolumn{5}{|c|}{ Multiplex PCR: } \\
\hline LES1 nestF & tttggtgatgatcggcttagc & \multirow[t]{2}{*}{289} & \multirow{4}{*}{$\begin{array}{l}95^{\circ} \mathrm{C}, 4 \text { min then } 30 \text { cycles: } \\
95^{\circ} \mathrm{C}, 30 \mathrm{~s} ; 58^{\circ} \mathrm{C}, 30 \mathrm{~s} ; 72^{\circ} \mathrm{C}, 30 \mathrm{~s} \\
\text { final extension step, } 72^{\circ} \mathrm{C}, 7 \mathrm{~min}\end{array}$} & \multirow[t]{2}{*}{ [25] } \\
\hline LES1nestR & tgtggaagcgatcagtct & & & \\
\hline Clust6nestF & ggatcgacgtggcataatctg & \multirow[t]{2}{*}{410} & & \multirow[t]{2}{*}{ [25] } \\
\hline Clust6nestR & acgattctccggcatgcagcg & & & \\
\hline 4 tot1F & gctcatgagtggctgacaac & \multirow[t]{2}{*}{105} & & \multirow[t]{2}{*}{ This study } \\
\hline 4 tot1R & tcttgggcagagaaccattc & & & \\
\hline \multicolumn{5}{|l|}{ Q-PCR: } \\
\hline 2 pro3F & caagccctgtctggattttc & \multirow[t]{2}{*}{102} & $95^{\circ} \mathrm{C}, 10 \mathrm{~min}$; then 40 cycles: & \multirow[t]{2}{*}{ This study } \\
\hline $2 p r o 3 R$ & gagacaggttgggagggagt & & $95^{\circ} \mathrm{C}, 10 \mathrm{~s} ; 60^{\circ} \mathrm{C}, 15 \mathrm{~s} ;$ & \\
\hline 3 tot1F & cgcaggtaccaccagacttt & \multirow[t]{2}{*}{122} & & \multirow[t]{2}{*}{ This study } \\
\hline 3 tot1R & catgtccagcaggttcaaaa & & & \\
\hline 3 pro3F & gcggatgttctcaaacgaat & \multirow[t]{2}{*}{134} & & \multirow[t]{2}{*}{ This study } \\
\hline 3 pro3R & cgggagaagcaatgacctac & & & \\
\hline 4 tot1F & gctcatgagtggctgacaac & \multirow[t]{2}{*}{105} & & \multirow[t]{2}{*}{ This study } \\
\hline $4 \operatorname{tot} 1 \mathrm{R}$ & tcttgggcagagaaccattc & & & \\
\hline 4pro3F & tcgtgctgtgctgatctttt & \multirow[t]{2}{*}{172} & & \multirow[t]{2}{*}{ This study } \\
\hline 4 pro3R & agcagtgccagttgatgttg & & & \\
\hline \multicolumn{5}{|c|}{ Preparation of DIG-labeled probes: } \\
\hline$\varphi 2$ intDIGF & tgcctatctaacggggttca & \multirow[t]{2}{*}{1097} & $95^{\circ} \mathrm{C}, 4$ min. 30 cycles: & \multirow[t]{2}{*}{ This study } \\
\hline$\varphi 2$ intDIGR & gaagcaaccgagaagtggag & & $\begin{array}{l}95^{\circ} \mathrm{C}, 30 \mathrm{~s} ; 55^{\circ} \mathrm{C}, 30 \mathrm{~s} ; 72^{\circ} \mathrm{C}, 1 \mathrm{~min} \mathrm{~s} \text {; } \\
\text { final extension step, } 72^{\circ} \mathrm{C}, 7 \mathrm{~min}\end{array}$ & \\
\hline$\varphi 3 i n t D I G F$ & ggatcatgtagcgggaaaga & \multirow[t]{2}{*}{874} & & \multirow[t]{2}{*}{ This study } \\
\hline$\varphi 3$ intDIGR & agaacctggcgaaagtctga & & & \\
\hline$\varphi 4 C I D I G F$ & atcgttaattggcacggaat & \multirow[t]{2}{*}{893} & & \multirow[t]{2}{*}{ This study } \\
\hline$\varphi 4 C I D I G R$ & acagcaacggatttccactc & & & \\
\hline
\end{tabular}

tot $=$ to quantify total phage copies; pro = to quantify total phage copies.

pathogen complex 200 protocol). Q-PCR was performed using six specific primer sets to differentiate between prophage and total copies of each phage.

\section{Real-time Q-PCR}

Q-PCR was used to quantify LES phages by comparing the number of specific amplicon copies in extracted DNA from induction experiments to a concentration gradient of known standards. Primer sets with the prefixes, "tot" (total) and "pro" (prophage) were designed to amplify unique regions within, and flanking, each LES phage genome (Figure 1D). All primer sequences and amplification details are listed in Table 4. Amplicon copy number $\mu \mathrm{l}^{-1}$ was calculated using the formula [(6.023 $\mathrm{x}$ $\left.10^{23} \times[\mathrm{DNA}] \mathrm{g} / \mathrm{ml}\right) /($ molecular weight of product $\left.)\right] /$ 1,000 [55]. Molecular weight was calculated as number of base pairs $\times 6.58 \times 10^{2} \mathrm{~g}$. A 10 -fold dilution series of each DNA standard was prepared for quantification of phage numbers in each sample.

Q-PCR reactions (25 ul) contained 1 uM each primer pair and $1 \mathrm{X}$ Rotorgene-SYBR green supermix
(QIAGEN). Phage numbers were quantified from DNA samples $(1 \mu \mathrm{l})$ in triplicate using a Rotorgene cycler (QIAGEN). Q-PCR data were analyzed using Rotorgene Q series software 1.7 (QIAGEN). Total phage and prophage numbers from each sample were quantified in separate reactions using "tot" and "pro" primer sets for each phage and comparing fluorescent signals to those from standard concentration gradients. The level of free phage in a given sample was calculated by subtracting prophage numbers from total phage numbers.

\section{Statistical analysis}

Specific phage sequences were quantified in triplicate from each of 3 experimental replicates using Q-PCR, and technical replicates were averaged prior to analyses. Differences in phage numbers, with and without norfloxacin and between time-points were analysed using separate ANOVAs for each phage, fitting induction (2 levels), time (2 levels) and their interaction as fixed factors. 


\section{Isolation of PAO1 lysogens}

PAO1 LES phage lysogens (PLPLs) were isolated from turbid islands in the centre of well-separated plaques using a sterile toothpick and streaked on to Columbia agar (Oxoid) to obtain single colonies. Individual lysogen colonies were analysed by multiplex PCR assays to confirm the presence of LES prophages.

\section{Immunity assays}

Lawns of PAO1 and each PLPL were created by adding mid-exponential phase $\left(\mathrm{OD}_{600} 0.5\right)$ cultures $(100 \mathrm{ul})$ to molten $0.4 \%(\mathrm{v} / \mathrm{v})$ agar and pouring onto Columbia agar plates to set. A 10-fold dilution series of each purified phage suspension $\left(10^{10}-10^{3}\right.$ p.f.u $\left.\mathrm{ml}^{-1}\right)$ was spotted (20 ul) onto lawns of each host. Countable plaques were observed at varying dilutions depending on the phagehost combination. The efficiency of plating (eop) value was calculated as the ratio of assay titre/most permissive titre. The most permissive titre was obtained on nonlysogenic PAO1.

\section{Southern blot analysis}

Southern analysis was performed as previously described [56]. Specific probes were prepared using the digoxigenin (DIG) PCR labelling kit (Roche). DIG-labelled probes were designed to hybridize targets within either the LES $\phi 2$ int gene, the LES $\phi 3$ int gene, or the LES $\phi 4$ $c \mathrm{I}$ gene using primers: $\phi 2$ intDIG F/R; $\phi 3 \operatorname{int} \mathrm{DIG} \mathrm{F} / \mathrm{R}$ and $\phi 4 c I D I G ~ F / R ~(T a b l e ~ 4)$. Bacterial genomic DNA was extracted using a Wizard Genomic DNA extraction kit (Promega) and digested using PstI, AcuI or DraIII (NEB) according to the manufacturer's instructions. Probes were hybridised to digested genomic DNA as described previously [53]. Hybridized probe was detected using alkaline phosphatase-conjugated antiDIG antibody $(1: 10,000)$ and CPDstar substrate (1:100) (Roche) according to the manufacturer's instructions.

\section{Competing interests}

The authors declare that they have no competing interests.

\section{Authors' contributions}

CJ designed the study; carried out the purification and characterisation of the LES phages and rates of induction and drafted the manuscript. JL carried out initial induction of the phages from the native host. HK and CJ carried out the host range study. AH clone-typed each clinical P. aeruginosa isolate. $J C$ prepared samples for electron microscopy of LES $\varphi 2$ and LES $\varphi 3 . M B$ and CW jointly conceived of the study and participated in its design and coordination and helped to draft the manuscript. All authors read and approved the final manuscript.

\section{Acknowledgements}

This work was supported by the Wellcome Trust (089215/Z/09/Z).

Thanks to Brian Getty (Institute of Infection and Global Health, University of Liverpool) for performing the electron microscopy; Dr Heather Allison for helpful discussions and to Professor Angus Buckling and Dr Rob Jackson for kindly supplying pil mutants and environmental Pseudomonas strains respectively.

\section{Author details}

'Institute of Infection and Global Health, University of Liverpool, 8 West Derby Street, Liverpool L69 7BE, UK. ${ }^{2}$ Department of Biology, University of York, York YO10 5DD, UK.

Received: 15 May 2012 Accepted: 19 September 2012 Published: 21 September 2012

\section{References}

1. Hardalo C, Edberg SC: Pseudomonas aeruginosa: assessment of risk from drinking water. Crit Rev Microbiol 1997, 23:47-75.

2. Stover CK, Pham XQ, Erwin AL, Mizoguchi SD, Warrener P, Hickey MJ, Brinkman FS, Hufnagle WO, Kowalik DJ, Lagrou M, et al: Complete genome sequence of Pseudomonas aeruginosa PA01, an opportunistic pathogen. Nature 2000, 406:959-964.

3. Gjodsbol K, Christensen JJ, Karlsmark T, Jorgensen B, Klein BM, Krogfelt KA: Multiple bacterial species reside in chronic wounds: a longitudinal study. Int Wound J 2006, 3:225-231.

4. Nasser S, Mabrouk A, Maher A: Colonization of burn wounds in Ain Shams University Burn Unit. Burns 2003, 29:229-233.

5. Chitkara YK, Feierabend TC: Endogenous and exogenous infection with Pseudomonas aeruginosa in a burns unit. Int Surg 1981, 66:237-240.

6. Hutchison ML, Govan JR: Pathogenicity of microbes associated with cystic fibrosis. Microbes Infect 1999, 1:1005-1014.

7. Hoiby N, Ciofu O, Bjarnsholt T: Pseudomonas aeruginosa biofilms in cystic fibrosis. Future Microbiol 2010, 5:1663-1674.

8. Hassett DJ, Korfhagen TR, Irvin RT, Schurr MJ, Sauer K, Lau GW, Sutton MD, Yu H, Hoiby N: Pseudomonas aeruginosa biofilm infections in cystic fibrosis: insights into pathogenic processes and treatment strategies. Expert Opin Ther Targets 2010, 14:117-130.

9. Fothergill JL, Walshaw MJ, Winstanley C: Transmissible strains of Pseudomonas aeruginosa in Cystic Fibrosis lung infections. Eur Respir $J$ 2012, 40:227-238.

10. Cheng K, Smyth RL, Govan JR, Doherty C, Winstanley C, Denning N, Heaf DP, van Saene H, Hart CA: Spread of beta-lactam-resistant Pseudomonas aeruginosa in a cystic fibrosis clinic. Lancet 1996, 348:639-642.

11. McCallum SJ, Corkill J, Gallagher M, Ledson MJ, Hart CA, Walshaw MJ: Superinfection with a transmissible strain of Pseudomonas aeruginosa in adults with cystic fibrosis chronically colonised by $P$ aeruginosa. Lancet 2001, 358:558-560.

12. Al-Aloul M, Crawley J, Winstanley C, Hart CA, Ledson MJ, Walshaw MJ: Increased morbidity associated with chronic infection by an epidemic Pseudomonas aeruginosa strain in CF patients. Thorax 2004, 59:334-336.

13. Panagea S, Winstanley C, Parsons YN, Walshaw MJ, Ledson MJ, Hart CA: PCR-based detection of a cystic fibrosis epidemic strain of Pseudomonas aeruginosa. Mol Diagn 2003, 7:195-200.

14. Scott FW, Pitt TL: Identification and characterization of transmissible Pseudomonas aeruginosa strains in cystic fibrosis patients in England and Wales. J Med Microbiol 2004, 53:609-615.

15. Aaron SD, Vandemheen KL, Ramotar K, Giesbrecht-Lewis T, Tullis E, Freitag A, Paterson N, Jackson M, Lougheed MD, Dowson C, et al: Infection with transmissible strains of Pseudomonas aeruginosa and clinical outcomes in adults with cystic fibrosis. JAMA 2010, 304:2145-2153.

16. Winstanley C, Langille MG, Fothergill JL, Kukavica-Ibrulj I, Paradis-Bleau C, Sanschagrin F, Thomson NR, Winsor GL, Quail MA, Lennard N, et al: Newly introduced genomic prophage islands are critical determinants of in vivo competitiveness in the Liverpool Epidemic Strain of Pseudomonas aeruginosa. Genome Res 2009, 19:12-23.

17. Kwan T, Liu J, Dubow M, Gros P, Pelletier J: Comparative genomic analysis of 18 Pseudomonas aeruginosa bacteriophages. J Bacteriol 2006, 188:1184-1187.

18. Kuzio J, Kropinski AM: O-antigen conversion in Pseudomonas aeruginosa PAO1 by bacteriophage D3. J Bacteriol 1983, 155:203-212.

19. Rehmat S, Shapiro JA: Insertion and replication of the Pseudomonas aeruginosa mutator phage D3112. Mol Gen Genet 1983, 192:416-423.

20. Ceyssens PJ, Lavigne R: Bacteriophages of Pseudomonas. Future Microbiol 2010, 5:1041-1055.

21. Holloway BW, Cooper GN: Lysogenic conversion in Pseudomonas aeruginosa. J Bacterio/ 1962, 84:1321-1324. 
22. Hayashi T, Baba T, Matsumoto H, Terawaki Y: Phage-conversion of cytotoxin production in Pseudomonas aeruginosa. Mol Microbiol 1990, 4:1703-1709.

23. Rice SA, Tan CH, Mikkelsen PJ, Kung V, Woo J, Tay M, Hauser A, McDougald D, Webb JS, Kjelleberg S: The biofilm life cycle and virulence of Pseudomonas aeruginosa are dependent on a filamentous prophage. ISME J 2009, 3:271-282.

24. Fothergill JL, Mowat E, Walshaw MJ, Ledson MJ, James CE, Winstanley C: Effect of antibiotic treatment on bacteriophage production by a cystic fibrosis epidemic strain of Pseudomonas aeruginosa. Antimicrob Agents Chemother 2011, 55:426-428.

25. Fothergill $\lrcorner$, Mowat E, Ledson MJ, Walshaw MJ, Winstanley C: Fluctuations in phenotypes and genotypes within populations of Pseudomonas aeruginosa in the cystic fibrosis lung during pulmonary exacerbations. J Med Microbiol 2010, 59:472-481.

26. Ojeniyi B, Birch-Andersen A, Mansa B, Rosdahl VT, Hoiby N: Morphology of Pseudomonas aeruginosa phages from the sputum of cystic fibrosis patients and from the phage typing set. An electron microscopy study. APMIS 1991, 99:925-930.

27. Brussow H, Canchaya C, Hardt WD: Phages and the evolution of bacterial pathogens: from genomic rearrangements to lysogenic conversion. Microbiol Mol Biol Rev 2004, 68:560-602.

28. Wiehlmann L, Wagner G, Cramer N, Siebert B, Gudowius P, Morales G, Kohler T, van Delden C, Weinel C, Slickers P, Tummler B: Population structure of Pseudomonas aeruginosa. Proc Natl Acad Sci U S A 2007, 104:8101-8106.

29. Miller RV, Pemberton JM, Clark AJ: Prophage F116: evidence for extrachromosomal location in Pseudomonas aeruginosa strain PAO. J Virol 1977, 22:844-847.

30. Refardt D: Within-host competition determines reproductive success of temperate bacteriophages. ISME J 2011, 5:1451-1460.

31. Priess H, Kamp D, Kahmann R, Brauer B, Delius H: Nucleotide sequence of the immunity region of bacteriophage Mu. Mol Gen Genet 1982, 186:315-321.

32. Berngruber TW, Weissing FJ, Gandon S: Inhibition of superinfection and the evolution of viral latency. J Virol 2010, 84:10200-10208.

33. Vanvliet F, Couturier M, Desmet L, Faelen M, Toussaint A: Virulent Mutants of Temperate Phage-Mu-1. Mol Gen Genet 1978, 160:195-202.

34. Benzer S: Fine Structure of a Genetic Region in Bacteriophage. Proc Natl Acad Sci U S A 1955, 41:344-354.

35. Susskind MM, Botstein D, Wright A: Superinfection exclusion by P22 prophage in lysogens of Salmonella typhimurium. III. Failure of superinfecting phage DNA to enter sieA+ lysogens. Virology 1974, 62:350-366.

36. Susskind MM, Botstein D: Superinfection exclusion by lambda prophage in lysogens of Salmonella typhimurium. Virology 1980, 100:212-216.

37. Susskind MM, Botstein D: Molecular genetics of bacteriophage P22. Microbiol Rev 1978, 42:385-413.

38. Heo YJ, Chung IY, Choi KB, Lau GW, Cho YH: Genome sequence comparison and superinfection between two related Pseudomonas aeruginosa phages, D3112 and MP22. Microbiology 2007, 153:2885-2895.

39. Brown SP, Le Chat L, De Paepe M, Taddei F: Ecology of microbial invasions: amplification allows virus carriers to invade more rapidly when rare. Curr Biol 2006, 16:2048-2052.

40. Irvin RT, Doig P, Lee KK, Sastry PA, Paranchych W, Todd T, Hodges RS: Characterization of the Pseudomonas aeruginosa pilus adhesin: confirmation that the pilin structural protein subunit contains a human epithelial cell-binding domain. Infect Immun 1989, 57:3720-3726.

41. OToole GA, Kolter R: Flagellar and twitching motility are necessary for Pseudomonas aeruginosa biofilm development. Mol Microbiol 1998 30:295-304.

42. Mattick JS: Type IV pili and twitching motility. Annu Rev Microbiol 2002, $56: 289-314$.

43. Whitchurch CB, Mattick JS: Characterization of a gene, pilU, required for twitching motility but not phage sensitivity in Pseudomonas aeruginosa. Mol Microbiol 1994, 13:1079-1091.

44. Brockhurst MA, Buckling A, Rainey PB: The effect of a bacteriophage on diversification of the opportunistic bacterial pathogen, Pseudomonas aeruginosa. Proc Biol Sci 2005, 272:1385-1391.
45. Chibeu A, Ceyssens PJ, Hertveldt K, Volckaert G, Cornelis P, Matthijs S, Lavigne R: The adsorption of Pseudomonas aeruginosa bacteriophage phiKMV is dependent on expression regulation of type IV pili genes. FEMS Microbiol Lett 2009, 296:210-218.

46. Mowat E, Paterson S, Fothergill JL, Wright EA, Ledson MJ, Walshaw MJ, Brockhurst MA, Winstanley C: Pseudomonas aeruginosa population diversity and turnover in cystic fibrosis chronic infections. Am J Respir Crit Care Med 2011, 183:1674-1679.

47. Taylor TB, Buckling A: Competition and dispersal in Pseudomonas aeruginosa. Am Nat 2010, 176:83-89.

48. Rahme LG, Stevens EJ, Wolfort SF, Shao J, Tompkins RG, Ausubel FM: Common virulence factors for bacterial pathogenicity in plants and animals. Science 1995, 268:1899-1902

49. Salunkhe P, Smart CH, Morgan JA, Panagea S, Walshaw MJ, Hart CA, Geffers R, Tummler B, Winstanley C: A cystic fibrosis epidemic strain of Pseudomonas aeruginosa displays enhanced virulence and antimicrobial resistance. J Bacteriol 2005, 187:4908-4920.

50. Fothergill JL, White J, Foweraker JE, Walshaw MJ, Ledson MJ, Mahenthiralingam E, Winstanley C: Impact of Pseudomonas aeruginosa genomic instability on the application of typing methods for chronic cystic fibrosis infections. J Clin Microbiol 2010, 48:2053-2059.

51. Stewart RM, Wiehlmann L, Ashelford KE, Preston SJ, Frimmersdorf E, Campbell BJ, Neal TJ, Hall N, Tuft S, Kaye SB, Winstanley C: Genetic characterization indicates that a specific subpopulation of Pseudomonas aeruginosa is associated with keratitis infections. J Clin Microbiol 2011, 49:993-1003.

52. Mahenthiralingam E, Coenye T, Chung JW, Speert DP, Govan JR, Taylor P, Vandamme P: Diagnostically and experimentally useful panel of strains from the Burkholderia cepacia complex. J Clin Microbiol 2000, 38:910-913.

53. Allison HE, Sergeant MJ, James CE, Saunders JR, Smith DL, Sharp RJ, Marks TS, McCarthy AJ: Immunity profiles of wild-type and recombinant shigalike toxin-encoding bacteriophages and characterization of novel double lysogens. Infect Immun 2003, 71:3409-3418.

54. Ackermann H-W, Heldal M: Basic electron microscopy of aquatic viruses. In Manual of Aquatic Viral Ecology. Edited by Wilhelm SW, Weinbauer MG, Suttle CA, Waco TX. American Society of Limnology and Oceanography, Inc; 2010:182-192.

55. Yin JL, Shackel NA, Zekry A, McGuinness PH, Richards C, Putten KV, McCaughan GW, Eris JM, Bishop GA: Real-time reverse transcriptasepolymerase chain reaction (RT-PCR) for measurement of cytokine and growth factor mRNA expression with fluorogenic probes or SYBR Green I. Immunol Cell Biol 2001, 79:213-221.

56. Southern EM: Detection of specific sequences among DNA fragments separated by gel electrophoresis. J Mol Biol 1975, 98:503-517.

doi:10.1186/1471-2180-12-216

Cite this article as: James et al:: Differential infection properties of three inducible prophages from an epidemic strain of Pseudomonas aeruginosa. BMC Microbiology 2012 12:216.

\section{Submit your next manuscript to BioMed Central and take full advantage of:}

- Convenient online submission

- Thorough peer review

- No space constraints or color figure charges

- Immediate publication on acceptance

- Inclusion in PubMed, CAS, Scopus and Google Scholar

- Research which is freely available for redistribution 